\title{
Experimental Study on Mechanical Behavior of Lean Cemented Sand and Gravel Material in Unloading and Reloading Paths
}

\author{
Jie Yang $\mathbb{D}^{1},{ }^{1}$ An-yu Yang, ${ }^{2,3}$ Yan-gong Shan, ${ }^{4}$ Miao-miao Yang, ${ }^{1}$ \\ Jin-lei Zhao, ${ }^{5}$ and Hang Yu (i) ${ }^{1}$ \\ ${ }^{1}$ School of Transportation and Civil Engineering, Nantong University, Nantong 226019, China \\ ${ }^{2}$ Nanjing Hydraulic Research Institute, Nanjing 210024, China \\ ${ }^{3}$ National Research Institute for Rural Electrification, Ministry of Water Resources of People's Republic of China, \\ Hangzhou 310012, China \\ ${ }^{4}$ Nanjing Branch of Jiangsu Province Hydrology and Water Resources Investigation Bureau, Nanjing 210008, China \\ ${ }^{5}$ Jiangsu Surveying and Design Institute of Water Resources Co., Ltd., Yangzhou 225127, China \\ Correspondence should be addressed to Hang Yu; yuhang@ntu.edu.cn
}

Received 12 September 2020; Revised 30 December 2020; Accepted 11 January 2021; Published 20 January 2021

Academic Editor: Zbyšek Pavlík

Copyright $(2021$ Jie Yang et al. This is an open access article distributed under the Creative Commons Attribution License, which permits unrestricted use, distribution, and reproduction in any medium, provided the original work is properly cited.

Lean cemented sand and gravel (LCSG) materials are subjected to unloading-loading when an LCSG dam is opened for water drainage and then refilled or a roadbed base is subjected to repeated wheel loads. To investigate the behavior of the LCSG materials under loading-unloading, previous studies utilized the complete loading triaxial test. In contrast, in this study, the consolidated drained triaxial tests in the unloading and reloading paths for materials with cementing agent contents of 60 and $100 \mathrm{~kg} / \mathrm{m}^{3} \mathrm{under}$ different confining pressures, for which each curve generates three loading-unloading cycles, were applied to investigate the unloading and reloading mechanical behavior. Experimental results indicated that the unloading and reloading behavior of the LCSG materials produced stress-strain curves exhibiting a crescent-shaped hysteresis loop, which differs from that exhibited by coarse-grained soil. Although the shape of the crescent-like hysteresis loop was preserved as stress levels increasing, it gradually expanded. Compared with that of the typical triaxial test, the cohesive force and the increasing internal friction angle increased. Further, as the confining pressure increased, the crescent-like hysteresis loops tapered, shear strength increased linearly, and the modulus of resilience increased nonlinearly; the latter's rate of change, however, decreased. The change in volumetric strain was small during unloading as the stress level changed.

\section{Introduction}

With the increasing speed and scale of urbanization, the demand for stone materials in the construction of real estate, municipal, transportation, and water conservancy infrastructure has increased sharply, leading to the rapid rise and growth of the stone quarrying market; mountain excavations have become widespread. The ceaseless mining has had a negative impact on the ecology of mountainous areas, and a large quantity of waste stone materials is produced. To reduce the ecological damage and facilitate the disposal of the existing abandoned stone, research has been conducted to discover alternative uses for the abandoned stone. One way was adding a small amount of cementing agent content, typically less than $120 \mathrm{~kg} / \mathrm{m}^{3}$ in density, into the abandoned stone to form a material called lean cemented sand and gravel (LCSG) material. LCSG material is a type of concrete with low cementing agent content that can be used for dams, roads, and other construction projects $[1,2]$. This can effectively reduce the construction waste and thus decrease the negative impact of this waste on the environment. However, at present, the application of LCSG material is still in the preliminary stage of exploration, and its applicability in engineering remains to be investigated.

The determination of the mechanical properties of LCSG materials is helpful for the structural calculation of practical 
projects. The properties are generally investigated through mechanical tests. Sun et al. conducted experimental studies on the compressive and flexural properties of LCSG materials $[3,4]$. Further, they reported reference values for the material components, such as the cementing agent content, sand content, water-binder ratio, and aggregate gradation of LCSG materials. These studies systematically analyzed the strength characteristics and deformation modulus of LCSG materials under unconfined pressure. However, LCSG materials are used in engineering applications involving complex stress conditions, such as those experienced by dams or roadbed bases. Therefore, some scholars have performed static triaxial tests, which are typically used in geotechnical engineering, to study the mechanical properties of this type of roller-compacted concrete with low cementing agent content. Through triaxial tests on LCSG materials, $\mathrm{Wu}$ et al. [5] analyzed the peak strength, initial modulus, and other mechanical properties at different curing ages and confining pressures. Through triaxial shear tests, Younes et al. analyzed the characteristics of their stress-strain curve, including the strength, initial elastic modulus, and dilatancy by changing the confining pressure and cementing agent content [6-10]. Although there have been some reports of static triaxial shear tests on LCSG materials, most of these tests were carried out under complete loading conditions. Further, those research results do not reflect the unloading and loading mechanical properties of LCSG materials in real-life projects such as an LCSG dam that is opened for water drainage and then refilled or a roadbed base that is subjected to repeated wheel loads.

Understanding the unloading and reloading properties of LCSG materials would help to improve the reliability of the stress and deformation results for the unloading and reloading processes of LCSG dams and roadbed bases. Many studies have been carried out on clay, coarse-grained soil, or similar cementing materials, and some unloading and reloading properties of those materials have been acquired. Liu et al. [11] used an ultrasonic test system to deform and fracture coal rock and adopted cyclic loading and unloading tests to analyze the change in the amplitude, dominant frequency, and velocity. Zhang et al. [12] conducted cyclic loading-unloading triaxial tests of sandstones under different confining pressures to reveal the energy conversion mechanism from rock deformation to failure and establish energy conversion equations in different stress-strain stages. Li et al. [13] studied the mechanical properties of the sand in unloading and reloading paths and observed shrinkage of the sand during unloading. Xu et al. [14] investigated the loading-unloading shear behavior of three types of earth materials with different clay contents under different relative humidity levels and confining pressures. They showed that the mechanical characteristics of the Earth materials have a strong dependence on the ambient relative humidity at which the samples are conditioned and on the clay content. Zhu et al. $[15,16]$ conducted conventional triaxial loading and unloading tests on a variety of coarse-grained soils and analyzed the mechanical properties of coarse-grained soils under unloading-reloading conditions. Zhao et al. [17] studied the effect of loading-unloading paths on the shear strength and deformation of intact and completely decomposed granite soil samples collected from deep areas around subway tunnels using the triaxial consolidated drained test along a multistage loading-unloading path. They found that the coarse-grained soils experienced carrier shrinkage during unloading and the carrier shrinkage increased with increasing stress levels. Yang et al. [18] revealed the influence of the unloading and reloading path on the strength characteristics, deformation modulus, and other mechanical properties of polyurethane foam-reinforced rockfill materials by conducting triaxial tests on weathered granite soil under different unloading and reloading times. They used a medium triaxial shear apparatus to test the resilience modulus and analyzed the deformation characteristics of the materials under the unloading and reloading process; furthermore, they revealed the variation law of the deformation modulus. Xu et al. [19] explored the mechanical behavior and damage characteristics of frozen soil under different moisture contents by completing triaxial loadingunloading cycle tests. Xiao et al. [20] performed loading and unloading triaxial tests to study the failure strength and the failure modes of a rock-like material containing a preexisting fissure.

Nevertheless, research on the mechanical properties of LCSG materials under triaxial unloading and reloading is rare. Currently, the mechanical properties of the clay or coarse-grained soils in the unloading-loading path, including the modulus of resilience, are directly used for finite element calculations involving LCSG dams [21, 22].

However, owing to the material composition, including the cementing agent content and particle size of the LCSG material, the mechanical properties can be different from those of the materials characterized in these studies. This affects the reliability of the stress and deformation results obtained for LCSG dams or roadbed bases.

Thus, this study carried out unloading and reloading triaxial tests of LCSG materials with cementing agent contents of 60 and $100 \mathrm{~kg} / \mathrm{m}^{3}$ under confining pressures of $300,600,900$, and $1200 \mathrm{kPa}$. Based on the results of these tests, the triaxial stress-strain loading and unloading curves and volumetric strain-axial strain curves under different cementing agent contents and confining pressures were analyzed. Moreover, peak strength, modulus of resilience, and volume contraction or expansion during unloading and loading of LCSG materials were studied.

\section{Materials and Methods}

To investigate the mechanical behavior of LCSG material subjected to unloading and reloading under different confining pressures and stress levels, two different cementing agent contents (specifically, 60 and $100 \mathrm{~kg} / \mathrm{m}^{3}$, which are commonly used for LCSG dams) were considered.

2.1. Materials and Test Specimens. The raw components of the LCSG material used in this study were medium-sized sand, crushed stone, water, and Portland cement, which were the same as those used in previous static triaxial tests of 
LCSG $[8,9]$. The specific gravity of the medium-sized sand was 2.62 with a fineness modulus of 2.48 and a bulk density of $1450 \mathrm{~kg} / \mathrm{m}^{3}$. The specific gravity, bulk density, water content, and clay content of the crushed stone were 2.71, $1650 \mathrm{~kg} / \mathrm{m}^{3}, 0.01 \%$, and $0.01 \%$, respectively. The Portland cement was obtained from Anhui Digang Hailuo Cement Co., Ltd. The fineness of the cement was $2.26 \%$; the contents of $\mathrm{SO}_{3}$ and $\mathrm{MgO}$ in the cement, which are harmful mineral contaminants, were $2.56 \%$ and $1.78 \%$, respectively, and did not exceed the prescribed content levels. The mix proportions of each group of LCSG specimens are given in Table 1 $[8,9]$. The mix materials are shown in Figure 1.

2.2. Test Procedure. Two groups of LCSG specimens were used, with each group containing eight specimens. The two groups of specimens were each subjected to confining pressures of $300,600,900$, and $1200 \mathrm{kPa}$ in this study. Each specimen was $700 \mathrm{~mm}$ high and had a diameter of $300 \mathrm{~mm}$, as shown in Figure 1. The material composition, curing, and preparation methods of the specimens were the same as those of the conventional triaxial test specimens prepared using the LCSG material $[8,9]$. The LCSG specimens for the unloading and reloading triaxial tests were prepared, and the tests were conducted according to the relevant regulations stated in SL237-1999 [23]. The tests were conducted using a TYD-1500 dynamic triaxial tester at Nanjing Hydraulic Research Institute, as shown in Figure 2, which has a comprehensive precision index higher than $1 \%$. The instrument consists of five parts: hydraulic station and digital signal element, load cell, triaxial pressure chamber, pressure/ volume controller, and cylinder software. The maximum confining pressure of the instrument is $4.0 \mathrm{MPa}$, and the maximum axial load is $1500 \mathrm{kN}$.

The unloading and reloading triaxial compression tests were conducted using a strain-controlled triaxial compression apparatus, and the main test procedure was as follows. The prepared specimens were covered with a rubber membrane and placed in the triaxial testing instrument. The specimens were saturated using the hydrostatic head method. The consolidation stress ratio, $\sigma_{1} / \sigma_{3}$, was controlled to 1.0 to consolidate the specimens under the different confining pressures of $300,600,900$, and $1200 \mathrm{kPa}$. To ensure drained conditions, the specimens were sheared at a controlled axial deformation rate of $1 \mathrm{~mm} / \mathrm{min}$, which favored the drainage of water during the test. Unloading was initiated after loading to the set stress level; reloading to the next stress level was initiated after the deviatoric stress reached zero. Unloading refers to the gradual decrease in the axial load after the specimen was loaded to stress levels corresponding to $25 \%, 65 \%$, and $80 \%$ of the peak deviatoric stress, $q_{\text {max }}$, which was the maximum value of the deviatoric stress, $\sigma_{1}-\sigma_{3}$. Table 2 summarizes the details of the loadingunloading sequences. A drastic decrease in the deviatoric stress, $q=\sigma_{1}-\sigma_{3}$, after the appearance of the peak value or the collapse of the samples was considered a sign of failure.
The peak deviatoric stress was recorded as the shear strength of the samples.

\section{Test Results and Analysis}

3.1. Stress-Strain Curves for LCSG Material in Unloading and Reloading. Two specimens were tested under the same confining pressure in the same stress path. The stress-strain curves and peak strengths between the two specimens under the same confining pressure were essentially the same. According to the average of those test results under the same confining pressure, Figure 3 shows the stress-strain curves of the LCSG material in the unloading and reloading triaxial tests.

As shown in Figure 3, for the LCSG material with a cementing agent content of $100 \mathrm{~kg} / \mathrm{m}^{3}$, the loading part of the curves in the unloading-reloading triaxial test coincides with its stress-strain curves in the complete loading triaxial test, which is a typical triaxial test [8]. This indicates that the test results are reliable. However, the unloading curve does not coincide with the reloading curve of the LCSG material in the unloading-reloading path. A crescent-shaped hysteresis loop is formed that is slightly different from that observed for coarse-grained soils, the hysteresis loop of which is an elliptic curve $[15,16]$. The main reason is that, in the case of coarse-grained soils, only plastic deformation occurs in the unloading and reloading process; however, in the LCSG material, in addition to the plastic deformation, the cementing agent of the material imparts a certain viscosity to the aggregate particles. With an increasing stress level, the shape of the crescent-like hysteresis loop remains unchanged, but its size gradually increases, which indicates that the stress level affects the viscosity of the LCSG material to a certain extent. The crescent-like hysteresis loop of the LCSG material with a cementing agent content of $100 \mathrm{~kg} / \mathrm{m}^{3}$ is more evident and has a smaller width than that of the LCSG material with a cementing agent content of $60 \mathrm{~kg} / \mathrm{m}^{3}$. In addition, the shear strength of the samples with a cementing agent content of $100 \mathrm{~kg} / \mathrm{m}^{3}$ in the unloading and reloading path is higher than that in the complete loading path. The analysis results above indicate that the unloadingreloading process causes an internal hysteresis loop to occur in which the internal materials are reconstituted. Further, the external forces under the unloading-reloading process are more prominent than those in the typical triaxial test, when the LCSG material specimens are destroyed.

3.2. Volumetric Strain. Figure 4 shows the volumetric strain and axial strain curves of the LCSG material with cementing agent contents of 60 and $100 \mathrm{~kg} / \mathrm{m}^{3}$ in the unloading and reloading paths under different stress levels and confining pressures, as well as the curves of the LCSG material with a cementing agent content of $100 \mathrm{~kg} / \mathrm{m}^{3}$ in the complete loading path [9]. As shown in Figure 4, except the part after the maximum volumetric strain, the volumetric strain-axial 
TABLe 1: Details of the test specimens.

\begin{tabular}{|c|c|c|c|c|c|c|}
\hline \multirow{2}{*}{ ID } & \multirow{2}{*}{ Cement $\left(\mathrm{kg} / \mathrm{m}^{3}\right)$} & \multirow{2}{*}{ Water-cement ratio } & \multirow{2}{*}{ Sand $\left(\mathrm{kg} / \mathrm{m}^{3}\right)$} & \multicolumn{3}{|c|}{ Stone $\left(\mathrm{kg} / \mathrm{m}^{3}\right)$} \\
\hline & & & & $5-10(\mathrm{~mm})$ & $10-20(\mathrm{~mm})$ & $20-40(\mathrm{~mm})$ \\
\hline 1 & 60 & 1.0 & 477 & 340.8 & 596.4 & 715.7 \\
\hline 2 & 100 & 1.0 & 477 & 340.8 & 596.4 & 715.7 \\
\hline
\end{tabular}

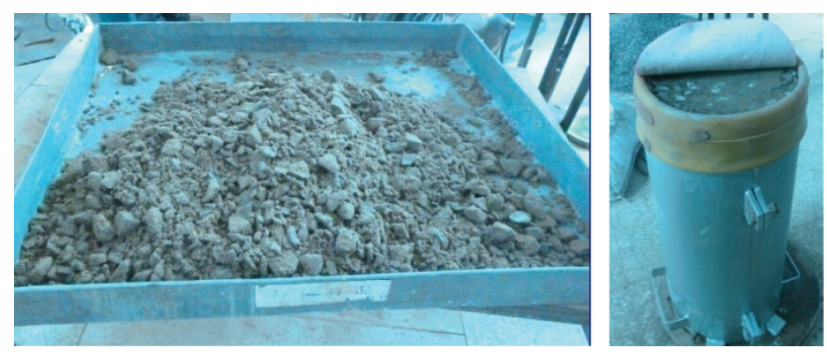

FIgURE 1: The specimen of LCSG material for the triaxial test.

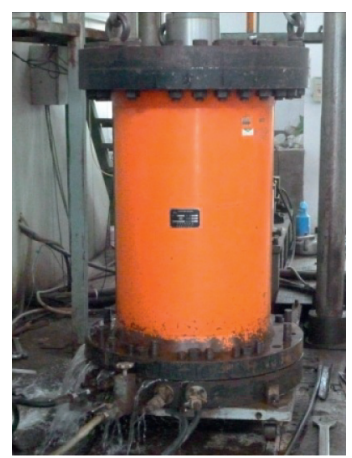

Figure 2: TYD-1500 dynamic triaxial tester.

TABLE 2: Multistage unloading-reloading sequences in the triaxial tests of LCSG materials with cementing agent contents of 60 and $100 \mathrm{~kg} / \mathrm{m}^{3}$.

\begin{tabular}{|c|c|c|c|}
\hline Test condition & Loading type & $s=q / q_{\max }$ & $\sigma_{3}(\mathrm{kPa})$ \\
\hline \multirow{3}{*}{ Consolidated drained } & \multirow{3}{*}{ Multistage unloading-reloading } & \multirow{3}{*}{$0 \longrightarrow 0.25 \longrightarrow 0 \longrightarrow 0.65 \longrightarrow 0 \longrightarrow 0.8 \longrightarrow 0 \longrightarrow 1$} & 300 \\
\hline & & & 600 \\
\hline & & & $\begin{array}{c}900 \\
1200\end{array}$ \\
\hline
\end{tabular}

strain curve in the loading stage of the LCSG material in the unloading and reloading process is basically the same as in the complete loading path; that is, it initially increases and then decreases, which indicates that the LCSG materials show initial shear shrinkage followed by shear expansion. With increasing confining pressures, their dilatancy becomes weaker, which can also be observed during the complete loading of LCSG materials with a cementing agent content of $100 \mathrm{~kg} / \mathrm{m}^{3}$. When the cementing agent content is $60 \mathrm{~kg} / \mathrm{m}^{3}$, the LCSG material appears to shrink in volume during the unloading process. When the confining pressure is $300 \mathrm{kPa}$, the specimen with a cementing agent content of $100 \mathrm{~kg} / \mathrm{m}^{3}$ expands during unloading. Further, when the confining pressure is higher than $600 \mathrm{kPa}$, unloading shrinkage of the LCSG material occurs.
3.3. Peak Strength. To explore the effect of the loading and unloading paths on the shear strength, similar with the research about sandstone [24], Figure 5 gives the final failure modes of specimens for LCSG material in the loading and unloading paths. The figure shows that the each specimen has a shear strain band which is the same with the final failure modes of specimens under the typical triaxial tests.

Figure 6 shows the shear strength of LCSG materials with a cementing agent content of 60 and $100 \mathrm{~kg} / \mathrm{m}^{3}$ in the unloadingreloading path and in the complete loading path. The shear strengths of LCSG materials with cementing agent contents of 60 and $100 \mathrm{~kg} / \mathrm{m}^{3}$ in the unloading and reloading path are higher than those found in the complete loading triaxial test. The test data show that the relationship between the shear strength and confining pressure is linear and can be fitted in a 


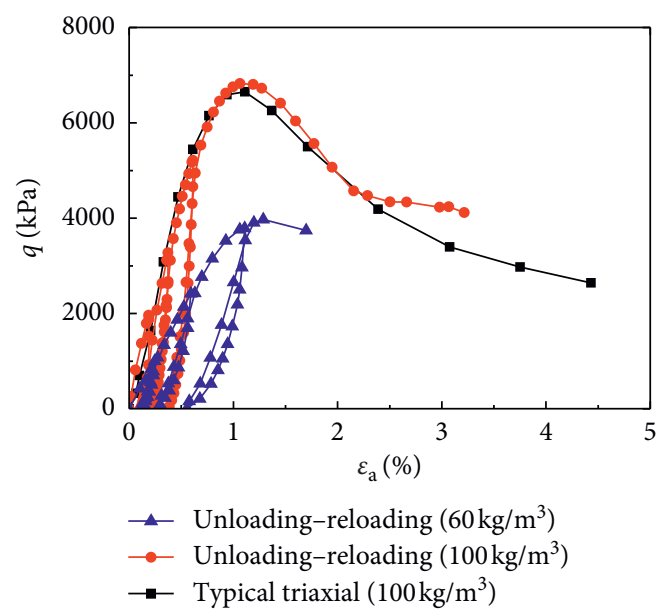

(a)

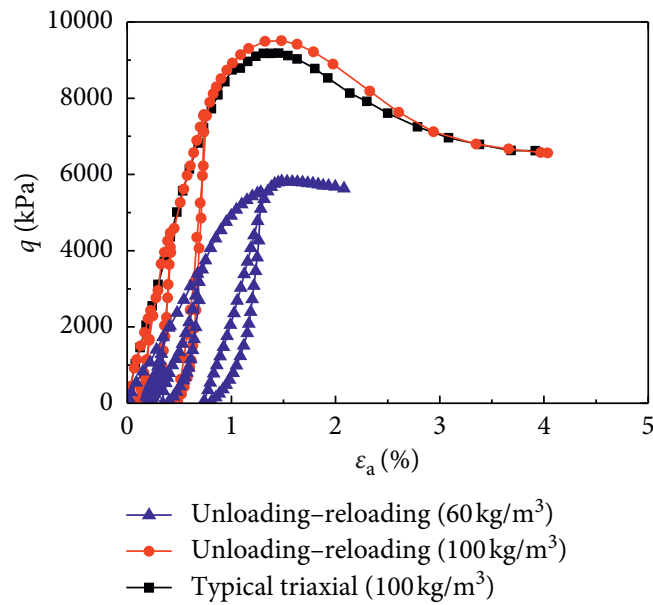

(c)

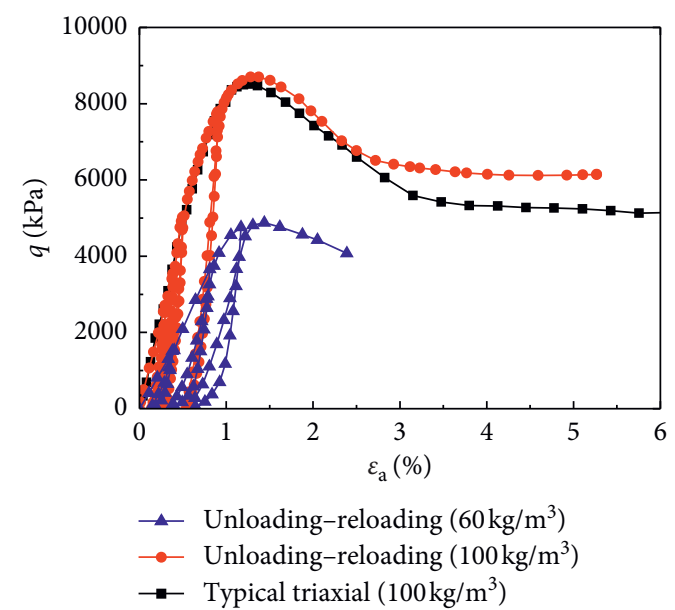

(b)
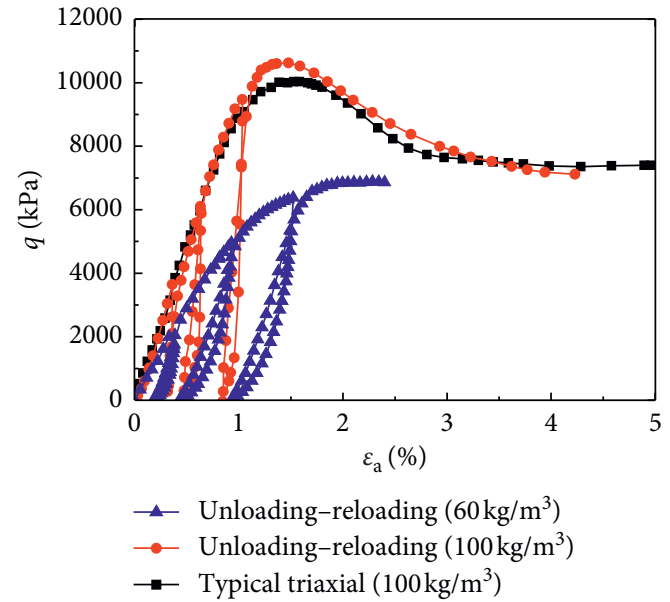

(d)

Figure 3: LCSG material stress-strain curves for different confining pressures. (a) $300 \mathrm{kPa}$. (b) $600 \mathrm{kPa}$. (c) $900 \mathrm{kPa}$. (d) $1200 \mathrm{kPa}$.

straight line; furthermore, the fitted straight line has a higher corresponding slope than that obtained for the complete loading test representing the internal friction angle of LCSG materials in the loading and unloading paths. The change in slope between the complete loading path and the unloading and reloading path is much higher than the change in the intercept. This shows that the shear strength of the LCSG material is promoted mainly by the friction angle, which is different from the increase in the shear strength of coarsegrained soil caused by the internal friction angle and cohesive force in the unloading and reloading path reported by $\mathrm{Chu}$ et al. [15]. A possible reason for the increase in the friction angle between particles is that bonded aggregate particles may have broken and resulted in more dislocations, which changes the direction of the load between the particles during the unloading and reloading process of the LCSG material. The relationship between the peak strength and confining pressure of consolidated sand and gravel with a single cementing agent content under unloading and reloading conditions can still be directly expressed using the classic Mohr-Coulomb criterion [8]. Although the relationship between the strength and confining pressure of recycled aggregate concrete [25], which is a material similar to LCSG material, is nonlinear, it can also be expressed as a linear relationship within a certain confining pressure range, which is similar to the relationship between the strength and confining pressure of LCSG material and reflects the rationality of the relationship in this paper.

3.4. Deformation Characteristics. The deformation moduli of the LCSG material and the carrier shrinkage during unloading are the most distinctly different characteristic indexes between the unloading and reloading tests and typical tests. This study focused on these indicators.

3.4.1. Modulus of Resilience. The modulus of resilience in triaxial unloading and reloading is one of the most important characteristic indexes for geotechnical materials. The ratio of the stress increment and axial strain increment during the unloading and reloading process is used to obtain the unloading modulus, which is calculated as follows:

$$
E_{u r}=\frac{\Delta \sigma_{1}}{\Delta \varepsilon_{1}}=\frac{\Delta\left(\sigma_{1}-\sigma_{3}\right)}{\Delta \varepsilon_{1}}
$$




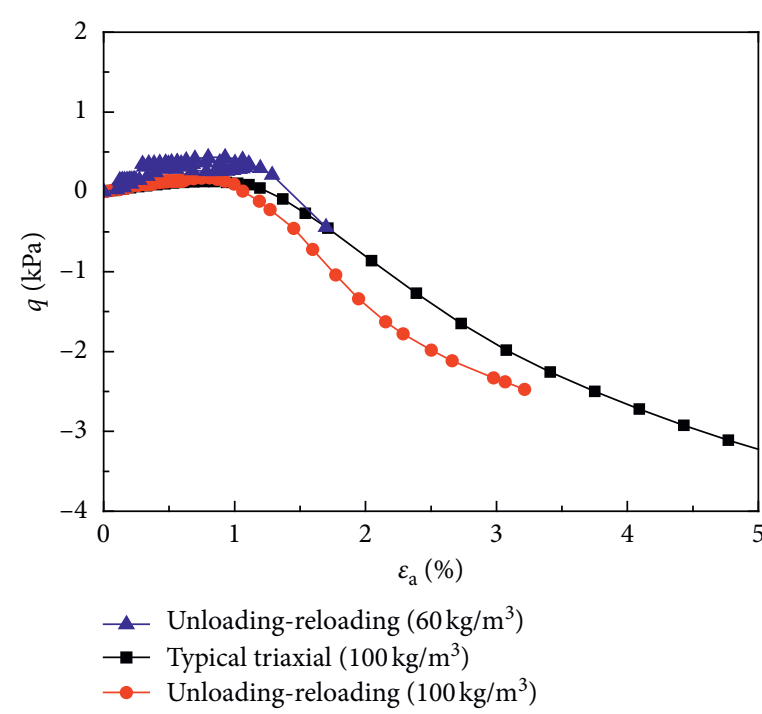

(a)

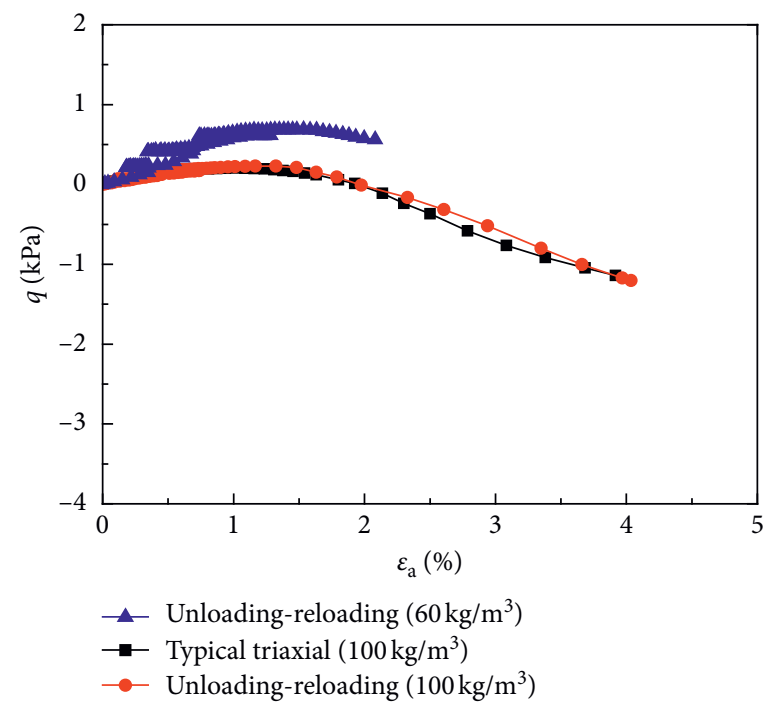

(c)

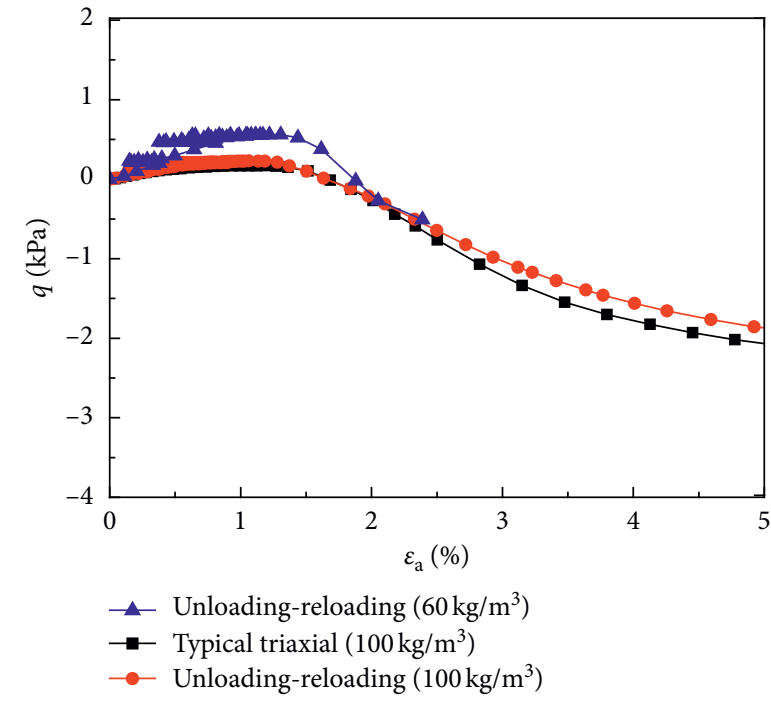

(b)

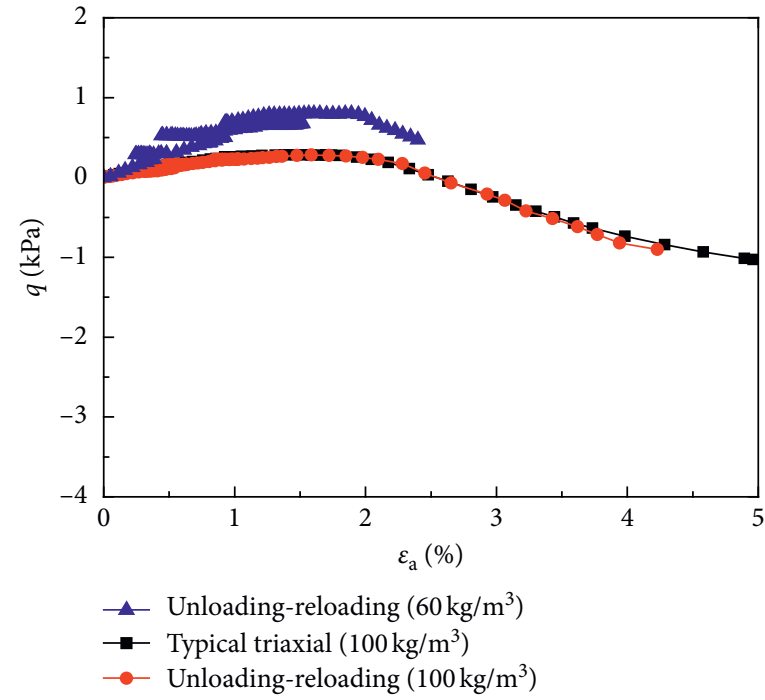

(d)

FIGURE 4: Volumetric strain-axial strain curves for different confining pressures of LCSG material. (a) $300 \mathrm{kPa}$. (b) $600 \mathrm{kPa}$. (c) $900 \mathrm{kPa}$. (d) $1200 \mathrm{kPa}$.
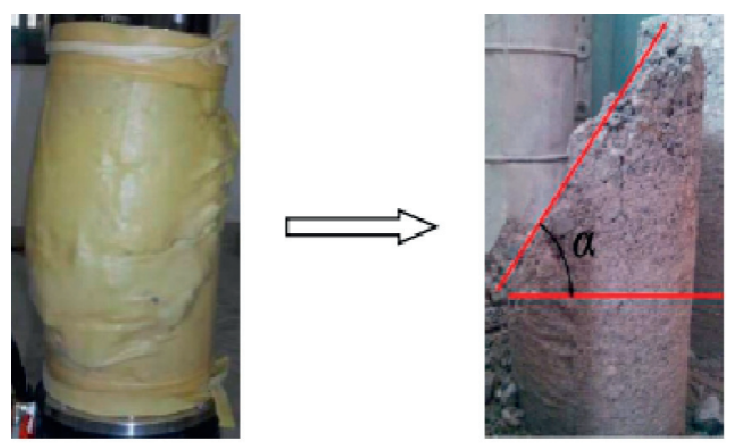

FIGURE 5: The final failure modes of specimens for LCSG material.

Figures 7 and 8 show that the unloading and loading curves, respectively, at each stage, can be divided into three phases: initial curve, intermediate linear, and end curve. In terms of stress, the initial and end curve phases of the LCSG material with a cementing agent content of $100 \mathrm{~kg} / \mathrm{m}^{3}$ account for less than $10 \%$ of the total stage curve; in terms of strain, 


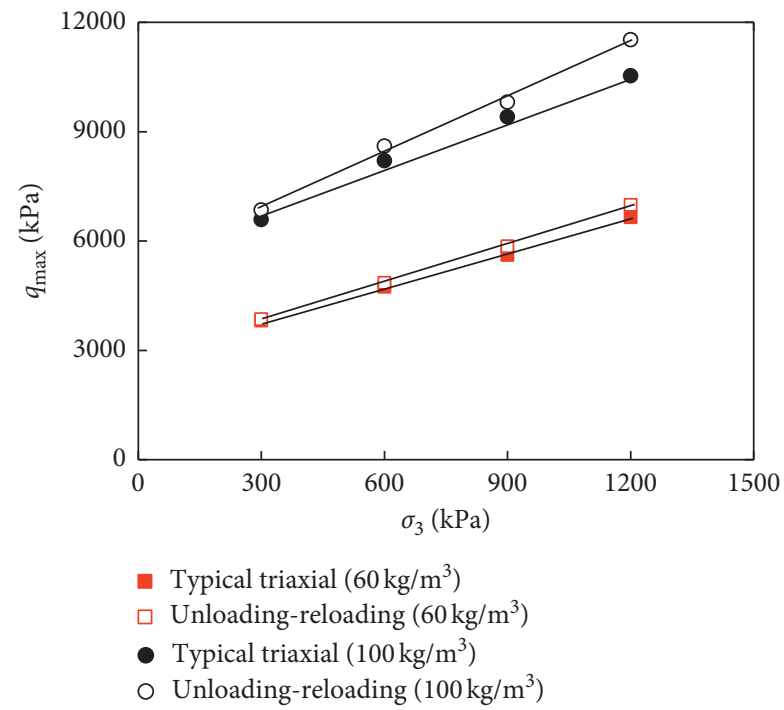

FIGURE 6: Relationship between shear strength $q_{\max }$ and confining pressure $\sigma_{3}$.

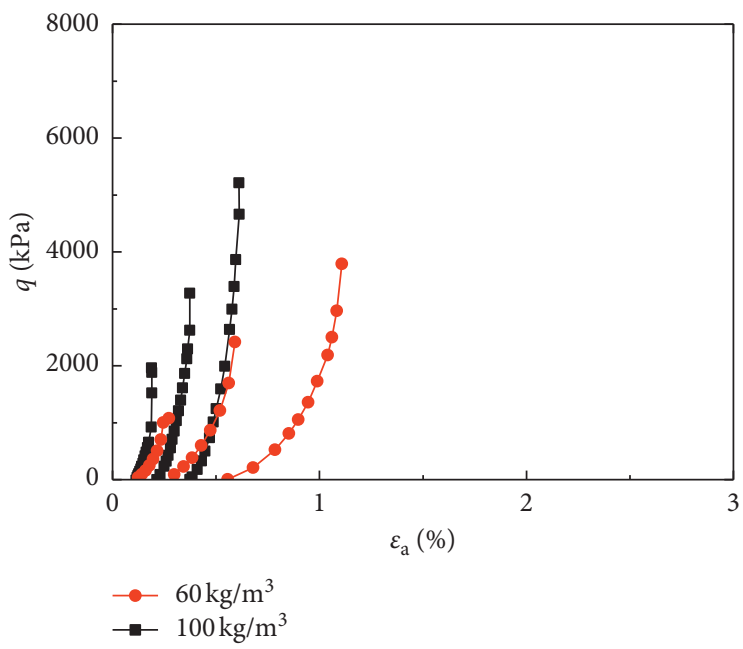

(a)

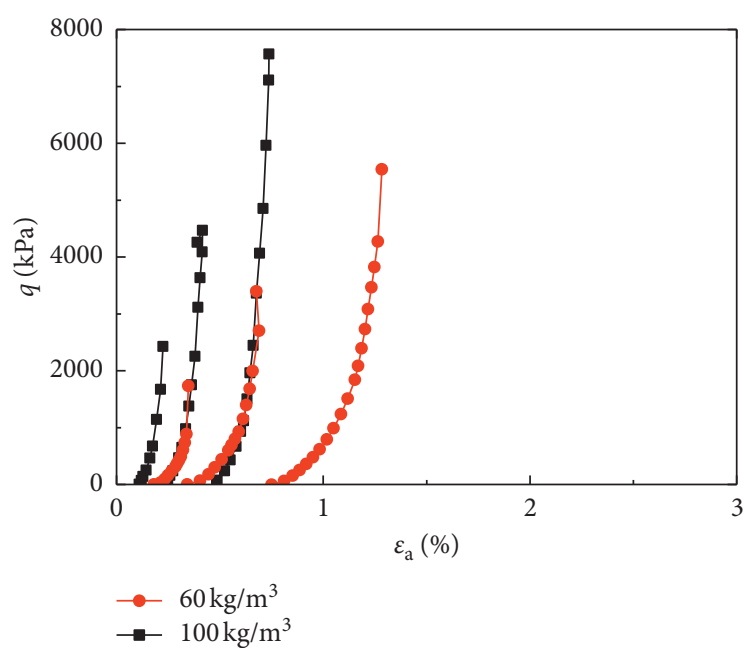

(c)

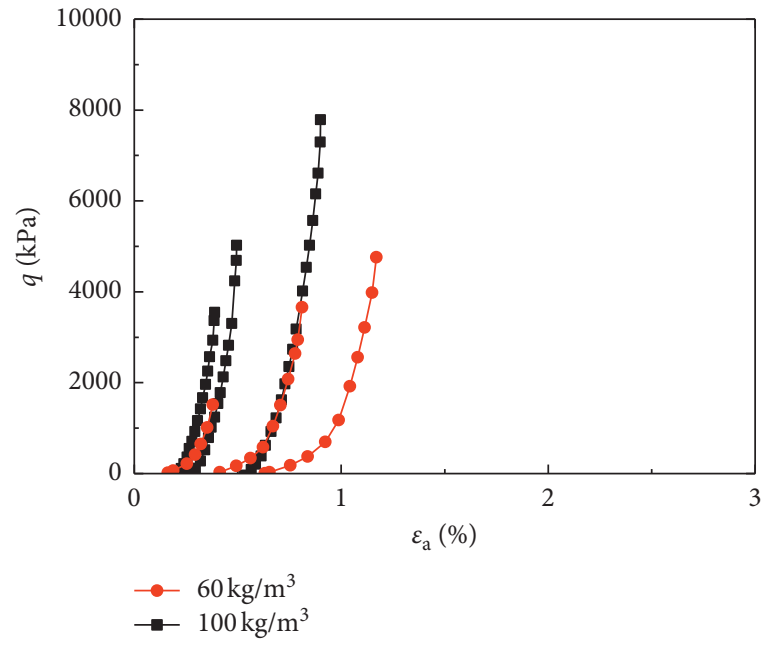

(b)

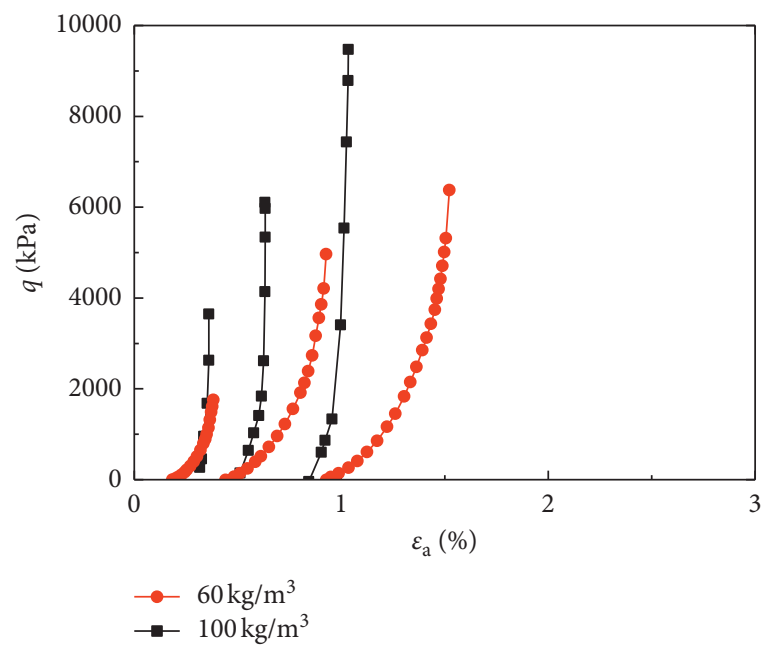

(d)

Figure 7: LCSG material unloading curves for different confining pressures. (a) $300 \mathrm{kPa}$. (b) $600 \mathrm{kPa}$. (c) $900 \mathrm{kPa}$. (d) $1200 \mathrm{kPa}$. 


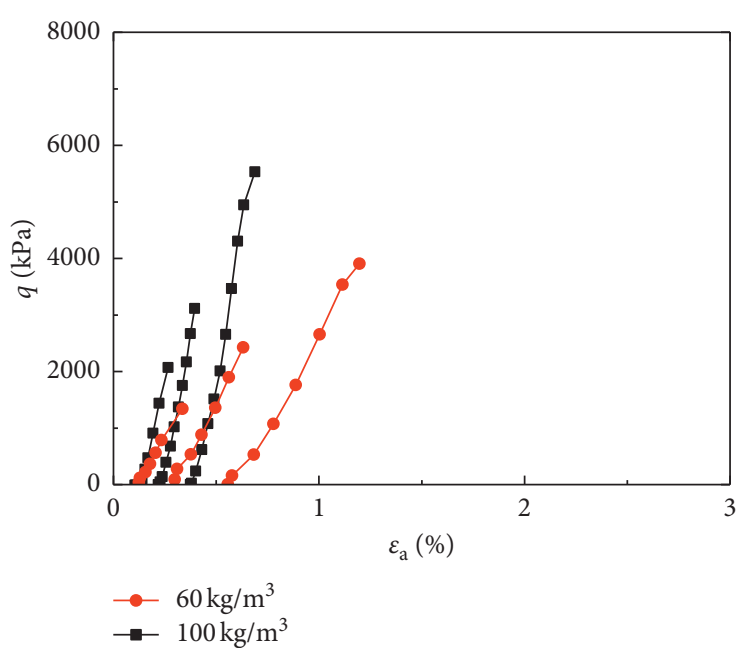

(a)

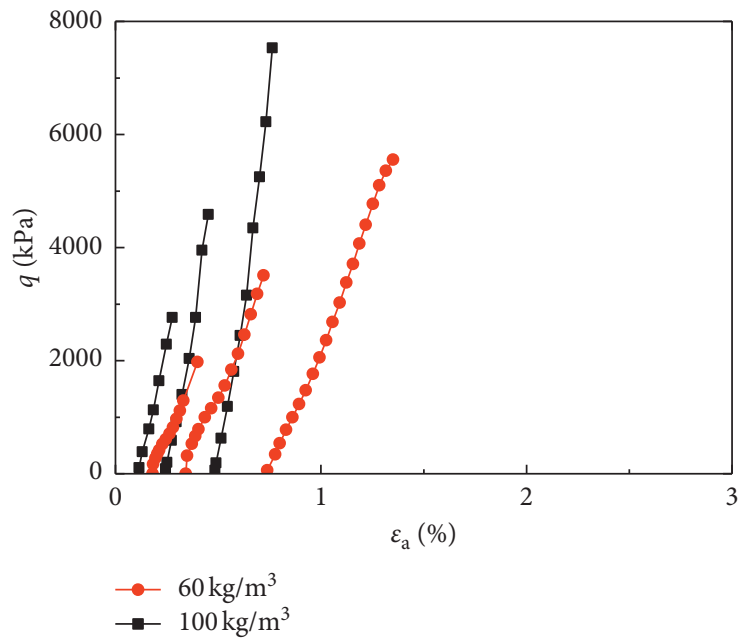

(c)

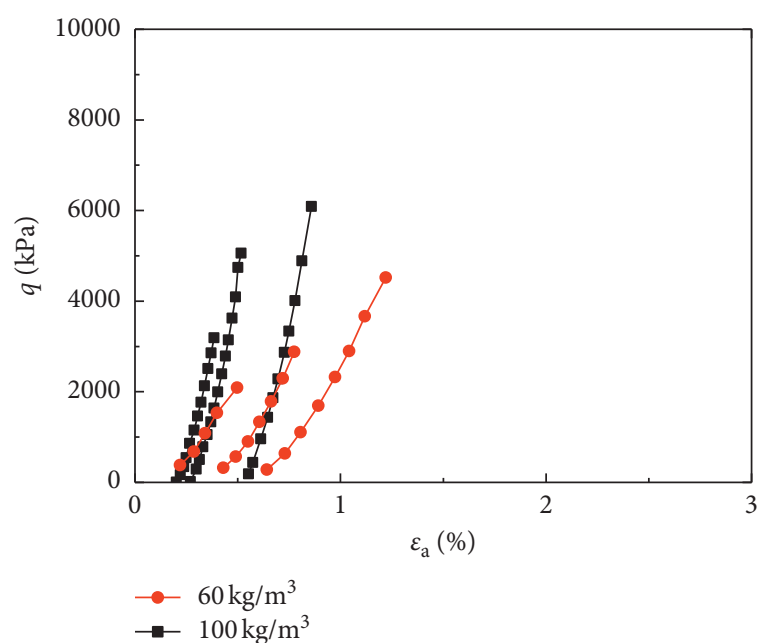

(b)

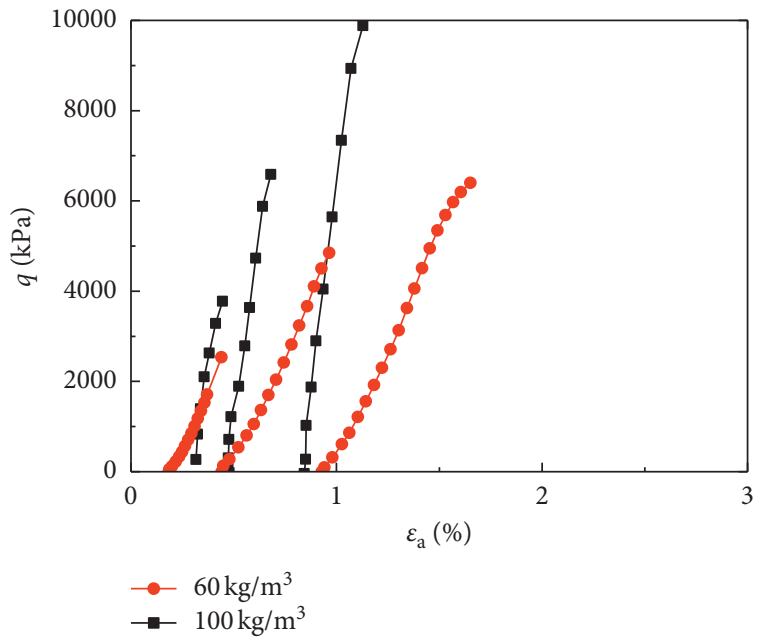

(d)

Figure 8: LCSG material reloading curves for different confining pressures. (a) $300 \mathrm{kPa}$. (b) $600 \mathrm{kPa}$. (c) $900 \mathrm{kPa}$. (d) $1200 \mathrm{kPa}$.

they account for less than $20 \%$ of the total stage curve. Thus, it is assumed that the loading and unloading curves are mainly composed of the intermediate linear phase. In addition, the variation coefficients of the slope in the linear region of the loading and unloading curves are less than 5\%. Although the slopes of the unloading and loading curves at each phase in the LCSG material with a cementing agent content of $60 \mathrm{~kg} /$ $\mathrm{m}^{3}$ considerably vary, the modulus of resilience follows the same trend as that of the LCSG material with a cementing agent content of $100 \mathrm{~kg} / \mathrm{m}^{3}$ for practical applications. Referring to relevant research on stratified backfill [26], the average value of the slopes in the linear regions of the loading and unloading curves is expressed as the modulus of resilience in this study. The calculation results for the modulus of resilience of LCSG materials with cementing agent contents of 60 and $100 \mathrm{~kg} / \mathrm{m}^{3}$ are summarized in Figure 9.

As shown in Figure 9, the confining pressure and stress level exhibit a certain influence on the deformation modulus. The deformation modulus increases with increasing confining pressures. The modulus of resilience under low confining pressures (i.e., 300 and $600 \mathrm{kPa}$ ) increases with increasing stress levels, whereas the modulus of resilience under high confining pressures (i.e., 900 and $1200 \mathrm{kPa}$ ) initially decreases and then increases with increasing stress levels. Although the modulus changes with the change in the stress level, the amplitude is less than $10 \%$. We can infer that the average modulus value of the LCSG material under different stress levels can be considered its modulus of resilience. The results are shown in Figure 10. Figure 10 shows that the modulus of resilience, $E_{\mathrm{ur}}$, increased nonlinearly with increasing confining pressure. This behavior is similar to that of unbound granular materials and cementtreated mixtures [27, 28], but it differs from the linear relationship between the modulus of resilience and the confining pressure of intact completely decomposed granite soils [14].

According to Figure 10, the modulus of resilience, $E_{u r}$, is calculated using the following equation, similar to the initial elastic modulus, $E_{i}$, in the Duncan-Chang constitutive model [18]: 


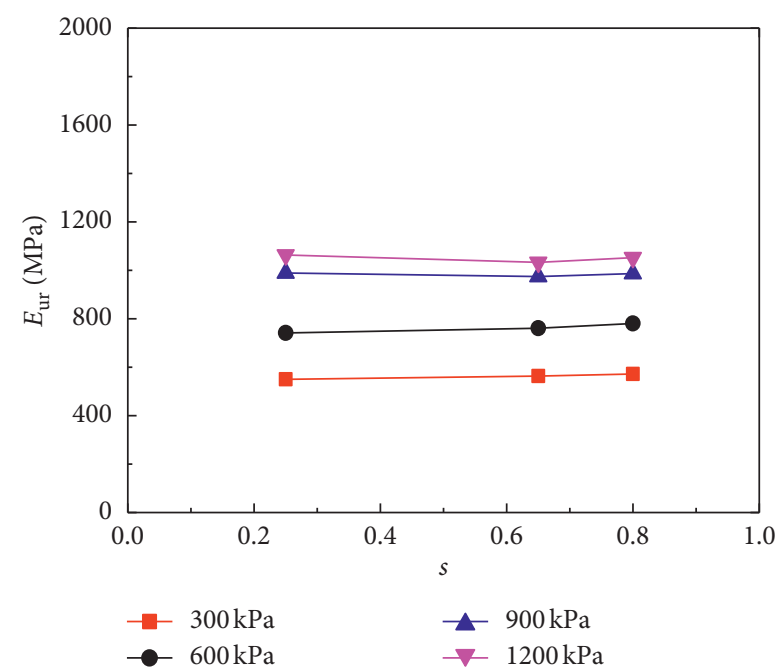

(a)

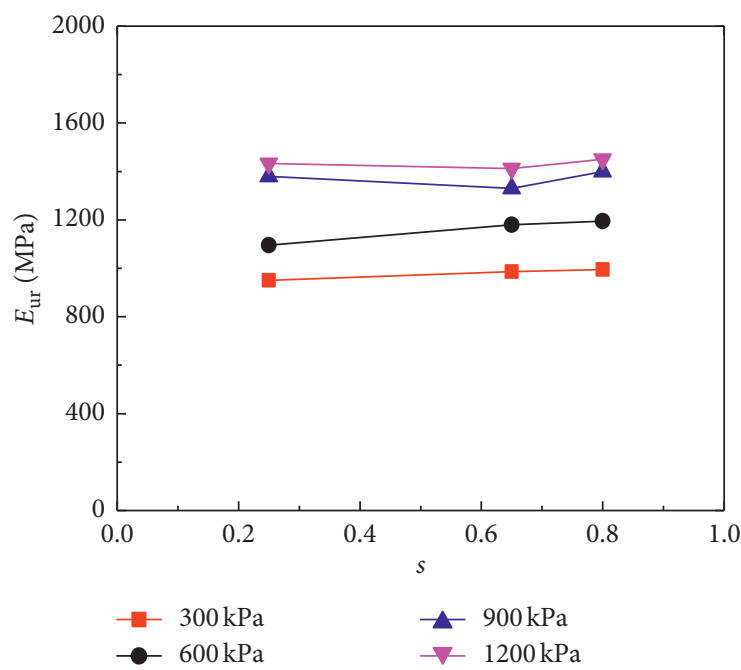

(b)

Figure 9: Relationship between the modulus of resilience, $E_{u \mathrm{r}}$, and stress level, $s$, for different cementing agent contents. (a) $60 \mathrm{~kg} / \mathrm{m}^{3}$. (b) $100 \mathrm{~kg} / \mathrm{m}^{3}$.

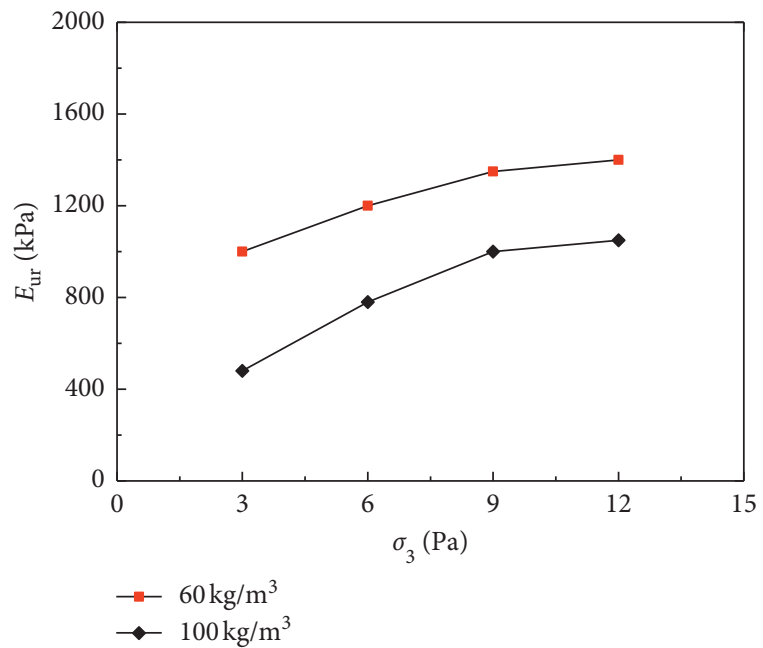

Figure 10: Relationship between the modulus of resilience, $E_{u r}$ and confining pressure, $\sigma_{3}$.

$$
E_{u r}=K_{u r} P_{a}\left(\frac{\sigma_{3}}{P_{a}}\right)^{n},
$$

where $K_{u r}$ is a dimensionless parameter related to the material type, the atmospheric pressure $\mathrm{Pa}$ is $100 \mathrm{kPa}, K_{u r} P_{a}$ represents the maximum modulus of resilience when the confining pressure is $100 \mathrm{~Pa}$, and $n$ represents the growth index of the maximum modulus of resilience.

However, when the confining pressure is zero, the initial modulus is zero in (2), and the result is inconsistent with the actual value of the modulus. Thus, the relationship between the initial modulus and confining pressure for the LCSG material, which was determined by Yang et al. [9], is expressed as follows:

$$
E_{u r}=K_{u r} P_{a}\left[\frac{\sigma_{3}+P_{a}}{P_{a}}\right]^{n}
$$

According to the test results, the ratio $N$ of the average value of the modulus of resilience, $E_{u r}$, and initial modulus, $E_{i}$, corresponding to stress levels under different confining pressures, was established. The relationship between $N$ and the confining pressure is plotted in Figure 11. As shown in Figure 8 , the value of parameter $N$ under different confining pressures and stress levels is the same for a particular cementing agent content, and the range of $N$ for the LCSG material with cementing agent contents of 60 and $100 \mathrm{~kg} / \mathrm{m}^{3}$ is between 1.3 and 2.2, which is lower than that of the geotechnical materials $[15,16]$.

3.4.2. Unloading Carrier Shrinkage. To analyze further the unloading shrinkage of the LCSG material under various stress levels and confining pressures, the volumetric increment during unloading, $\Delta \varepsilon_{\mathrm{v}}$, is acquired as follows:

$$
\Delta \varepsilon_{v}=\varepsilon_{v 2}-\varepsilon_{v 1}
$$

where $\varepsilon_{\mathrm{v} 2}$ and $\varepsilon_{\mathrm{v} 1}$ are the volume strain corresponding to a certain stress level in the shearing process and the volume strain corresponding to the axial deviatoric stress unloading to zero, respectively.

Based on (4), the volume of shrinkage after unloading under different confining pressures and stress levels is shown in Figure 12, where "-" indicates shrinkage and "+" indicates expansion. The unloading carrier of the LCSG material with a cementing agent content of $100 \mathrm{~kg} / \mathrm{m} 3$ showed body expansion when the confining pressure was $300 \mathrm{kPa}$. In all other cases, the specimens of LCSG material with cementing agent contents of 60 and $100 \mathrm{~kg} / \mathrm{m} 3$ show body shrinkage. As in the case of polymer rockfill materials, the unloading carrier shrinkage phenomenon is observed in the LCSG material because of cemented content filling the pores among particles. It is difficult for particles to cross over to adjacent particles and rearrange, which results in the body shrinkage phenomenon. Further, with decreasing confining pressure, the sample 


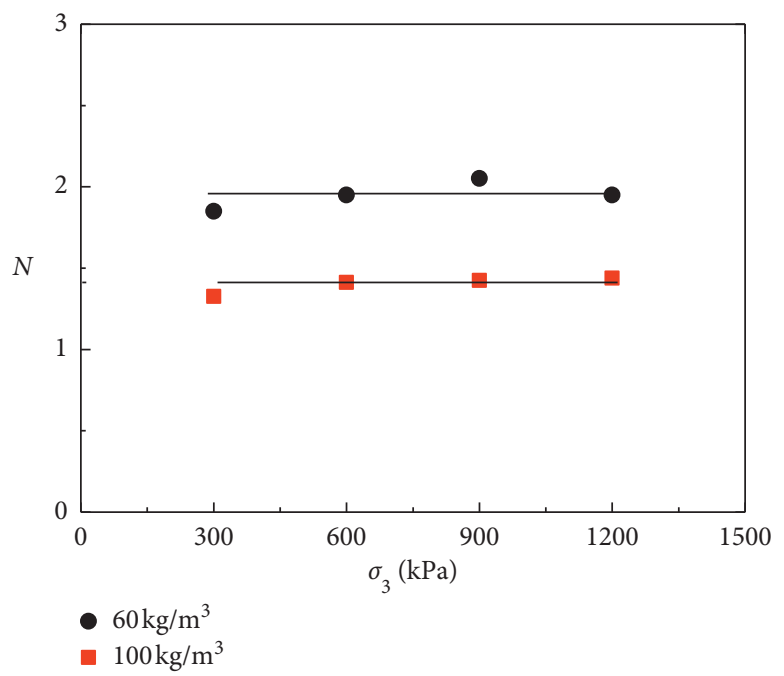

FIGURE 11: Relationship between parameter $N$ and confining pressure, $\sigma_{3}$.

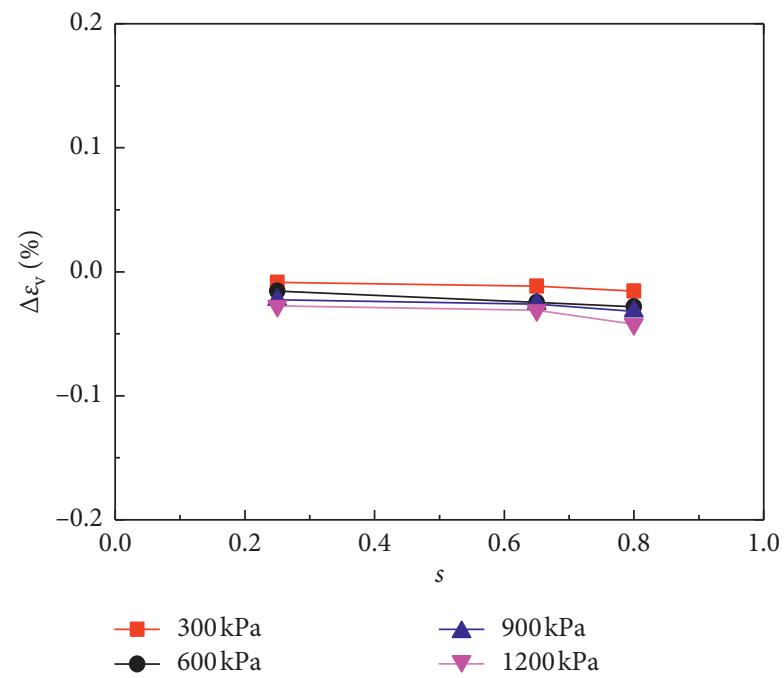

(a)

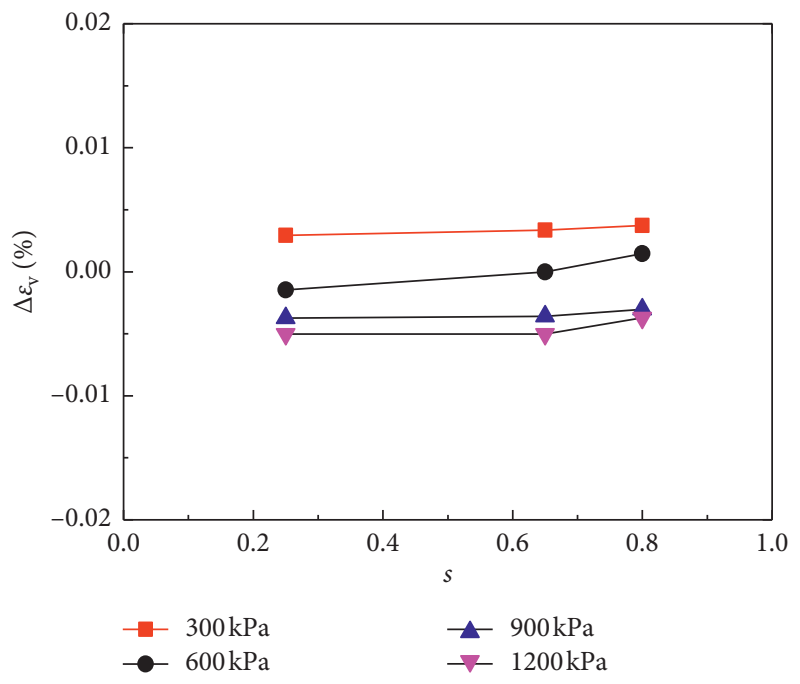

(b)

FIGURE 12: Relationship between volumetric increments during unloading and stress level, $s$, for different cementing agent contents. (a) $60 \mathrm{~kg} / \mathrm{m}^{3}$. (b) $100 \mathrm{~kg} / \mathrm{m}^{3}$.

unloading carrier shrinkage gradually weakens, and the phenomenon of unloading carrier expansion occurs for the LCSG material specimen with a cementing agent content of $100 \mathrm{~kg} / \mathrm{m} 3$. The LCSG material specimen with cementing agent content of $60 \mathrm{~kg} / \mathrm{m}^{3}$ under different confining pressures and stress levels exhibits body shrinkage, and, with decreasing confining pressure, the sample unloading carrier shrinkage gradually weakens. Under different stress levels, the change in volumetric strain is small. In this study, $\Delta \varepsilon_{\mathrm{v}}$ is assumed to be directly averaged for LCSG materials with cementing agent contents of 60 and $100 \mathrm{~kg} / \mathrm{m}^{3}$.

\section{Conclusions}

In this study, loading and unloading triaxial tests of LCSG materials with cementing agent contents of 60 and $100 \mathrm{~kg} / \mathrm{m}^{3}$ under different confining pressures $(300,600,900$, and $1200 \mathrm{kPa})$ and stress levels $(0.25,0.65$, and 0.80$)$ were carried out to investigate the resilience characteristics and change laws of the resilient modulus of LCSG materials. The following conclusions were drawn:

To ascertain the behavior of the LCSG materials under loading-unloading, the unloading and reloading triaxial tests of the materials under factors such as cementing agent 
contents and confining pressures, which differ from the typical triaxial tests on the mechanical properties of the LCSG materials conducted by other experts, were adopted. The comparison between the results of the test and the typical triaxial tests also reflects the practicality of the loading-unloading triaxial tests of the LCSG materials.

The stress-stain curves of LCSG materials in the unloading and reloading path exhibit crescent-shaped hysteresis loops that differ from those of rockfill materials. With increasing confining pressure and cementing agent content, the crescent-like hysteresis loops tapered. Further, with increasing stress levels, they maintained their crescent-like shape but gradually expanded.

The friction angle and cohesion of the LCSG materials under the unloading and reloading triaxial tests were larger than those of the typical rockfill material. Compared to the cohesive force, an increase in friction angle can further promote the shear strength of LCSG materials. However, with the increase in confining pressure, the shear strength still increased linearly.

As confining pressure increased, the modulus of resilience increased nonlinearly; the modulus of resilience also increased with stress levels. The different confining pressures had minimal influence on $N$ and the ratio of modulus of resilience to the initial modulus. The modulus of resilience of LCSG materials with cementing agent contents of 60 and $100 \mathrm{~kg} / \mathrm{m}^{3}$ is approximately $1.3-2.2$ times the corresponding initial modulus.

Except for the body expansion of the LCSG material under a confining pressure of $300 \mathrm{kPa}$, shrinkage occurred during unloading for the LCSG material with a cementing agent content of $100 \mathrm{~kg} / \mathrm{m}^{3}$, and, with increasing confining pressure, the body shrinkage of the specimens during the unloading process was more evident. The stress level has little effect on the volumetric increment during unloading for LCSG materials with cementing agent contents of 60 and $100 \mathrm{~kg} / \mathrm{m}^{3}$.

These results could serve as a crucial reference for numerical calculations involving LCSG dams, roadbed bases, and other reinforcement projects utilizing LCSG materials.

\section{Data Availability}

The test and calculated data used to support the findings of this study are available from the corresponding author upon request.

\section{Conflicts of Interest}

The authors declare no conflicts of interest.

\section{Acknowledgments}

This research was funded by the Basic Public Welfare Research Project of Zhejiang, Grant no. LGF20E090002, the Natural Science Foundation of the Higher Education Institutions of Jiangsu Province, Grant no. 18KJB130004, and the Natural Science Foundation of Jiangsu Province, Grant no. SBK2019022365.

\section{References}

[1] P. Londe and M. Lino, "The faced symmetrical hardfill dam: a new concept for RCC," International Water Power and Dam Construction, vol. 44, no. 2, pp. 19-24, 1992.

[2] J. S. Jia, N. Liu, C. Y. Zheng, F. L. Ma, Z. K. Du, and Y. Wang, "Research progress and engineering application of cemented granular dam," Journal of Water Conservancy, vol. 47, no. 3, pp. 315-323, 2016.

[3] M. Q. Sun, Study on Mechanical Properties, Durability and Dam Shape of Cemented Sand and Gravel, China water resources and hydropower press, Beijing, China, 2016.

[4] W. Feng, Studies on Cemented Sand and Gravel Dam Material and its Application, China Institute of Water Resources and Hydropower Research, Beijing, China, 2013.

[5] M. Wu, B. Du, Y. Yao, and X. He, "An experimental study on stress-strain behavior and constitutive model of hardfill material," Science China Physics, Mechanics and Astronomy, vol. 54, no. 11, pp. 2015-2024, 2011.

[6] Y. Amini and A. Hamidi, "Triaxial shear behavior of a cementtreated sand-gravel mixture," Journal of Rock Mechanics and Geotechnical Engineering, vol. 6, no. 5, pp. 455-465, 2014.

[7] H. Fu, S. S. Chen, H. Q. Han, H. Ling, and X. Cai, "Experimental study on static and dynamic properties of cemented sand and gravel," Chinese Journal of Geotechnical Engineering, vol. 37, pp. 357-362, 2015.

[8] Y. Yang, X. Li, X. Li, X. W. Guo, Y. L. Wu, and J. L. Zhao, "Shear strength and compression coefficient for conditioned sand subjected to earth chamber stress levels," Advances in Materials Science and Engineering, vol. 2018, Article ID 2531642, 11 pages, 2018.

[9] J. Yang, X. Cai, X. W. Guo, and J. L. Zhao, "Effect of cement content on the deformation properties of cemented sand and gravel material," Applied Sciences-Basel, vol. 9, no. 2369, pp. 1-16, 2019.

[10] N. Zhou, S. Y. Ouyang, Q. Q. Cheng, and F. Ju, "Experimental study on mechanical behavior of a new backfilling material: cement-treated marine clay," Advances in Materials Science and Engineering, vol. 2019, Article ID 1261694, 8 pages, 2019.

[11] D.-X. Li, W. Liu, D. Hao, Z. T. Liu, and X. Y. Xu, "Vibration antiresonance design for a spacecraft multifunctional structure," Shock and Vibration, vol. 2017, Article ID 7643451, 10 pages, 2017.

[12] M. Zhang, Q. Meng, and S. Liu, "Energy evolution characteristics and distribution laws of rock materials under triaxial cyclic loading and unloading compression," Advances in Materials Science and Engineering, vol. 2017, Article ID 5471571, 16 pages, 2017.

[13] G. X. Li and R. P. Guo, "The experimental study of volumetric contraction after unloading of soil and recover dilatancy," Chinese Journal of Geotechnical Engineering, vol. 22, no. 2, pp. 158-161, 2000.

[14] L. Xu, K. K. Wong, A. Fabbri, F. Champiré, and D. Branque, "Loading-unloading shear behavior of rammed earth upon varying clay content and relative humidity conditions," Soils and Foundations, vol. 58, no. 4, pp. 1001-1015, 2018.

[15] Y. F. Chu, J. G. Zhu, and H. Jia, "Experimental study of mechanical behaviour of coarse-grained soil in unloading and reloading," Rock and Soil Mechanics, vol. 33, no. 4, pp. 1061-1066, 2012. 
[16] J. G. Zhu, Y. L. Wang, H. Jia, and B. Zhang, "Experimental study on resilience behaviour of coarse grained soils," Chinese Journal of Geotechnical Engineering, vol. 33, no. 4, pp. 950954, 2011.

[17] Y. R. Zhao, H. Q. Yang, L. P. Huang, R. Chen, X. S. Chen, and S. Y. Liu, "Mechanical behavior of intact completely decomposed granite soils along multi-stage loading-unloading path," Engineering Geology, vol. 260, pp. 1-8, Article ID 105242, 2019.

[18] G. Yang, X. Sun, and Y. Y. Wang, "Tests on resilient behaviour of polymer rockfill materials," Rock and Soil Mechanics, vol. 39, no. 5, pp. 1669-1674, 2018.

[19] X. Xu, Q. Li, Y. Lai, W. Pang, and R. Zhang, "Effect of moisture content on mechanical and damage behavior of frozen loess under triaxial condition along with different confining pressures," Cold Regions Science and Technology, vol. 157, pp. 110-118, 2019.

[20] T. Xiao, M. Huang, and M. Gao, "Experimental study of the mechanical characteristics of a rock-like material containing a preexisting fissure under loading and unloading triaxial compression," Advances in Civil Engineering, vol. 2020, Article ID 9374352, 12 pages, 2020.

[21] X. Cai, J. Yang, X. W. Guo, and Y. L. Wu, "Elastoplastic constitutive model for cement-sand-gravel material," Chinese Journal of Geotechnical Engineering, vol. 38, no. 9, pp. 1569-1577, 2016.

[22] K. M. Wei, S. S. Chen, and G. Y. Li, "Elastoplastic model for cemented coarse-grained materials and its application," Chinese Journal of Geotechnical Engineering, vol. 41, no. 5, pp. 797-805, 2019.

[23] SL237-1999, Specification of Soil Test, Ministry of Water Resources of the People's Republic of China, Beijing, China, 1999.

[24] X. Jiang, P. Liu, F. Yan, Y. Yang, D. P. Xu, and G. L. Feng, "Failure performance of $3 \mathrm{dp}$ physical twin-tunnel model and corresponding safety factor evaluation," Rock Mechanics and Rock Engineering, vol. 9, pp. 1-20, Article ID 02244, 2020.

[25] P. Folino and H. Xargay, "Recycled aggregate concrete mechanical behavior under uniaxial and triaxial compression," Construction and Building Materials, vol. 56, pp. 21-31, 2014.

[26] J. Wang, W. Song, S. Cao, and Y. Tan, "Mechanical properties and failure modes of stratified backfill under triaxial cyclic loading and unloading," International Journal of Mining Science and Technology, vol. 29, no. 5, pp. 809-814, 2019.

[27] W. Fedrigo, W. P. Núñez, M. A. Castañeda López, T. R. Kleinert, and J. A. P. Ceratti, "A study on the resilient modulus of cement-treated mixtures of RAP and aggregates using indirect tensile, triaxial and flexural tests," Construction and Building Materials, vol. 171, pp. 161-169, 2018.

[28] N. Zhalehjoo, A. Tolooiyan, R. Mackay, and D. Bodin, "The effect of instrumentation on the determination of the resilient modulus of unbound granular materials using advanced repeated load triaxial testing," Transportation Geotechnics, vol. 14, pp. 190-201, 2018. 